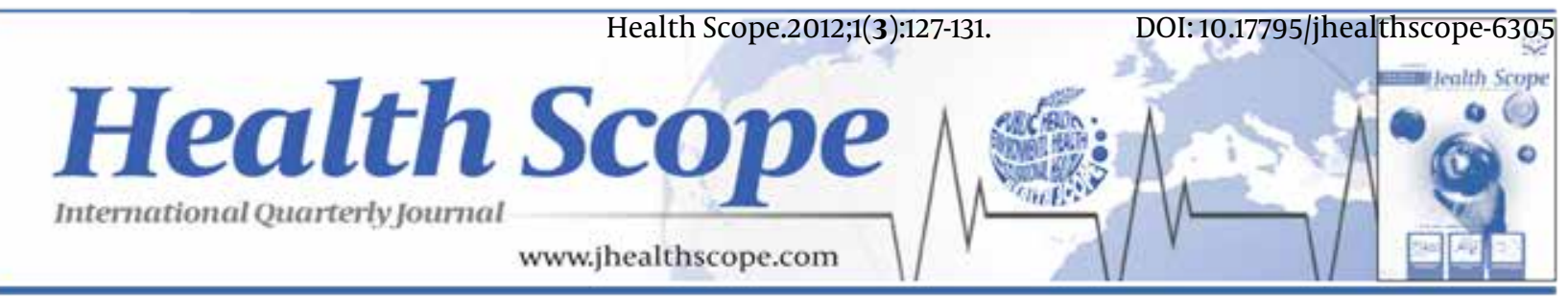

\title{
Determination of Hospital Waste Composition and Management in Amol City, Iran
}

\section{Omme Leila Rabeie ${ }^{1}$, Mohammad Bagher Miranzadeh ${ }^{2}$, Seyyedeh Hoorieh Fallah ${ }^{3}$, Sa- maneh Dehqan ${ }^{4}$, Zahra Moulana ${ }^{5}$, AbdolIman Amouei ${ }^{3}$, Ali Akbar Mohammadi ${ }^{3}$, Hossein Ali Asgharnia ${ }^{3}$, Mojtaba Babaei ${ }^{3}$}

${ }^{1}$ Department of Anesthesiag, Babol University of Medical Sciences, Babol, IR Iran

${ }^{2}$ Environmental Health Engineering Department, Kashan University of Medical sciences, Kashan, IR Iran

${ }^{3}$ Environmental Health Engineering Department, Babol University of Medical Sciences, Babol, IR Iran

${ }^{4}$ Environmental Health Engineering, Sari, IR Iran

${ }^{5}$ Laboratorial Sciences Department, Babol University of Medical Sciences, Babol, IR Iran

\section{A R T I C L E I N F O}

Article type:

Research Article

Article history:

Received: 10 May 2012

Revised: 30 May 2012

Accepted: 09 Jun 2012

Keywords:

Hospitals

Hazardous Waste

Waste Management

\begin{abstract}
A B S T R A C T
Background: Hospital wastes are potentially hazardous and infectious to humans and the environment; therefore, hospitals must manage and dispose of their waste properly. Objectives: The aim of this study was to determine the composition and management of waste in the north of Iran.

Materials and Methods: This cross-sectional, descriptive study was conducted on the status and composition of hospital wastes generated in three hospitals in Amol City (located in the north of Iran). During the study a total of three samples (a sample per month) were selected and analyzed for waste ingredients in each hospital. Some of the data was gathered by hospital personnel who completed questionnaire.

Results: Based on this study's findings the average rate of hospital waste generation was $3.1 \mathrm{~kg} /$ bed per day, of this $48.5 \%$ was non-hazardous and $51.5 \%$ was hazardous waste. In our study, the minimum and maximum component percentage of hospital wastes was for metal (1.07\%) and paper (17.9\%), respectively.

Conclusions: Based on the findings obtained, the rate of total waste generation in the Amol Hospital is similar in range to that of other Iranian hospitals, however, the hazardous fraction of this waste was high in comparison to other previous studies, and this is probably due to improper separation and management of the waste materials.
\end{abstract}

- Implication for health policy/practice/research/medical education:

The content of this article is useful for management of hospital wastes and selection of proper method to disposal of hazardous wastes by ministry of health.

Please cite this paper as:

Rabeie OL, Miranzadeh MB, Fallah SH, Dehqan S, Moulana Z, Amouei A, et al. Determination of Hospital Waste Composition and Management in Amol City, Iran. Health Scope. 2012; 1(3): 127-31.

${ }^{*}$ Corresponding author: Samaneh Dehqan, Environmental Health Engineering, Sari, Zip code: 48171-81555, plaque: 401 ,Mazandaran, Sari, IR Iran. Tel: +989117177356, Fax:+98-1112234367, E-mail: dehqans@yahoo.com 


\section{Background}

A hospital is a medical system which has been created in order to provide diagnostic, therapeutic and hygienic facilities for the recovery of outpatients and inpatients from various diseases. Nowadays, hospitals and medical institutions have experienced remarkable growth which has resulted in the generation of increased amounts of medical wastes (1). Medical wastes are potentially hazardous, infectious and toxic, and due to their harmful nature, improper handling and disposal may destroy the natural environment and disturb the balance of the ecosystem (2).Studies show that currently $450000 \mathrm{~kg}$ of medical waste is produced daily in Iran, and that they have infectivity potential for living creatures $(1,3)$. Increasing the size of hospitals and the widespread use of disposable items, will increase the amount of medical wastes generated (4).

In France, medical waste is divided into three categories according to the generation source, these include; special medical wastes, kitchen and semi-household wastes, and other kinds of medical wastes. In another classification system, medical waste is divided into six categories which consist of biological, human pathological wastes, human blood and blood products, sharps, unused sharps, and animal wastes (5). The most common classification of medical waste according to the World Health Organization (WHO)consists of seven categories including; ordinary wastes, pathological wastes, radioactive wastes, chemical wastes, infectious wastes, kitchen and semihousehold wastes and other kinds of medical wastes(4). Inadequate medical waste control and inattention to its collection, maintenance, transport and correct disposal, can result in specific problems which may threaten society and environment health(6). Medical waste, may contain vast quantities of microorganisms such as Staphylococcus aurous, tuberculosis and tetanus bacilli, hepatitis $A$ and $B$ and AIDS viruses, etc. these are significant infectious organisms and dangerous to human health (7).

In recent years hospital infections and the contamination of health center personnel with microorganisms, such as hepatitis B and AIDS viruses, has been one of the most important concerns of international organizations, especially WHO. According to researchers approximately $40 \%$ to $50 \%$ of medical wastes are hazardous and this can result in the transmission of hepatitis and AIDS viruses(8-10). Precise scientific investigations have shown that large numbers of infectious diseases have been engendered as a result of carelessness and indifference in the maintenance, transport and disposal of medical wastes (8). For example, the probability of being infected with AIDS and hepatitis viruses was $0.1 \%$ and $10 \%$, respectively, as the result of contact with contaminated syringes (11). In addition to microbial contamination of hospital waste, researchers estimate that there are approximately 630 different types of chemical materials used in hospi- tals, and about 300 of these are toxic and hazardous to people's health. A significant amount of medical waste is found in the shape of residues and non-control of their disposal, resulting in water, soil and air pollution. These toxins can result in the growth of vermin and dangerous microorganisms, which can develop into other potential sanitary hazards(6). In addition, the formation of toxic dioxin and furan gases from medical waste incineration can cause damage to human nervous and reproduction systems over a long period of time, and disposal of these wastes can result in soil, water and air pollution, because the leachate of medical waste is much more polluting than household waste leachate. $(7,12)$.

Due to the dangerous potential of hospital wastes, they should be treated before disposal. There are many ways to treat hospital wastes. Common clinical waste treatment systems are; incineration, steam autoclave, microwave, mechanical/chemical treatment, pyrolysis and plasma incineration (5). A great deal of research has been conducted in Iran and other countries on the management and physical composition of hospital wastes. Amol's hospitals which are covered by the Mazandaran University of Medical Sciences, with 480 beds and several departments, make a significant contribution to medical waste generation, and if these medical wastes are not managed correctly, they can create irrecoverable hazards to hospital personnel, society and the environment.

\section{Objectives}

The aim of this study was to determine the management status and physical composition of hospital waste in Amol City.

\section{Materials and Methods}

This cross-sectional, descriptive study has been conducted on the management status and physical composition of hospital wastes in Amol hospitals, which are covered by the Mazandaran University of Medical Sciences, for a three month period during 2011.The three hospitals studied included; Imam Reza, 17Shahrivar and Imam Ali, which are called hospital A, B and C in the text, respectively. During the study period, one sample per month from each hospital (a total of nine samples from three hospitals) were randomly selected and analyzed to determine their composition. For the physical analysis, the weight of each hospital waste sample was $120 \mathrm{~kg}$. Remaining data were gathered by filling a questionnaire that was designed and confirmed by the Iranian Heath and Treatment Ministry, through interviews with the hospital's environmental health personnel, during the study period. The parameters considered in this questionnaire included; hospital waste generation per bed per day, total daily amount of hospital waste generation, and type and disposal method of hospital waste. Finally SPSS software 


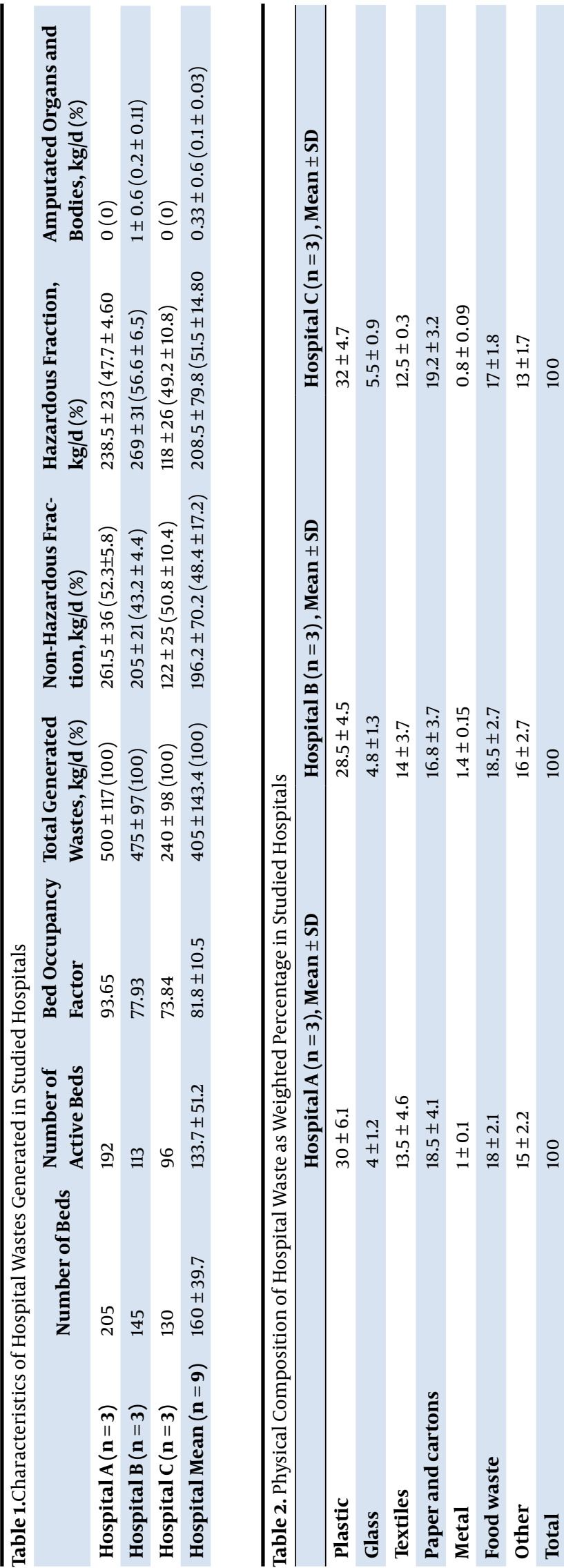

(Version 11.5, SPSS Inc. Corporation, and Chicago) and statistical indexes were used for analysis of the data obtained.

\section{Results}

In Table 1the data for the number of beds and waste generation weight for the three hospitals are shown. As reported in this table, the mean number of beds and occupancy rates in the studied hospitals were; 160 beds and $81.8 \%$, respectively. The mean weight of hospital waste generation in hospital A, B and C were; $500 \mathrm{~kg}, 475 \mathrm{~kg}$ and $240 \mathrm{~kg}$ per day, respectively. In addition, the percentage of the hazardous fraction of hospital waste in hospitals A, B and C were; $47.7 \%, 56.63 \%$ and $49.2 \%$, respectively. The mean rate of waste generation were; 2.6 (hospital A), 4.2 (hospital B) and 2.5 (hospital C) kg/bed per day. The results of physical analysis of the individual components in the hospital waste at the three hospitals are reported in Table 2.The results obtained in this study showed that the mean individual components of generated waste in the studied hospitals were; plastic $30.2 \%$, glass $4.8 \%$, textiles $13.4 \%$, paper $17.9 \%$, metal $1.07 \%$, food waste $17.8 \%$ and other materials $14.7 \%$. Regarding the above data, the maximum and minimum percentages of the components are related to paper and metal, respectively.

\section{Discussion}

Findings of this research showed that the average rate of hospital waste generation in the three studied hospital were between $2.5 \mathrm{~kg}$ to $4.2 \mathrm{~kg} /$ bed per day, that is similar to the level of waste generation in other countries such as; Brazil, India, Jordan and Turkey (1-5 kg/bed per day) $(10,13-15)$. According to a study in India the rate of medical waste generation was reported to be $2.31 \mathrm{~kg} /$ bed per day (16). On the other hand, waste generation in hospitals in some developed countries such as; the U.S.A, Netherlands, France and Argentina is reported to be $4.5 \mathrm{~kg}, 2.8$ $\mathrm{kg}, 2.7 \mathrm{~kg}$ and $2.7 \mathrm{~kg} /$ bed per day, respectively, which in most cases is close to our study findings (17).On the other hand, medical waste generation in some Asian countries has been reported as below this level; Bangladesh 0.8-1.67 $\mathrm{kg}$, Bhutan $0.27 \mathrm{~kg}$, India1-2 kg, Malaysia1.9 kg, Nepal 0.5 $\mathrm{kg}$, Pakistan $1.06 \mathrm{~kg}$, Sri Lanka $0.36 \mathrm{~kg}$, Thailand0.68 kg and Vietnam $2.27 \mathrm{~kg} /$ bed per day (18). In comparison the value findings of our study are low and that is probably due to differences in the levels of medical services and waste management in the different hospitals.

In addition, a study on the rate of medical waste generation in other Iranian hospitals has shown that the rate of waste generation were $7.42 \mathrm{~kg}, 3.43 \mathrm{~kg}$ and $3.23 \mathrm{~kg} / \mathrm{bed}$ per day in Yazd, Shiraz and Mahshahr cities, respectively. Regarding the aforementioned data, in the Yazd City Hospital this rate is very high in comparison to the results of the current study. This is probably due to a lack of knowl- 
edge and carelessness by hospital workers, applicants and patient's companions $(8,19)$. Research on medical waste generation in Semnan, Fars, Khuzestan and Tehran province hospitals showed that the average generation rate of hospital waste was $0.8-1.8 \mathrm{~kg}, 3.9 \mathrm{~kg}, 2.3 \mathrm{~kg}$ and 2.71 $\mathrm{kg} /$ bed per day, respectively, which shows a wide variation in range (20). The amount of hospital and health center wastes in Sabzevar has been reported to be $2.38 \mathrm{~kg} /$ bed per day (21). The obtained data revealed that the average fraction of hazardous, non-hazardous waste and amputated organs in Amol's city hospitals was 47.76\%, 51.17\% and $0.07 \%$, respectively. As reported in Table 2, the fraction of hazardous waste in hospital A, B and C were $47.7 \%$, $56.63 \%$ and $49.2 \%$, respectively. The amount of hazardous waste in this current study is greater than the amount of hazardous wastes generated in Bukan, Bushehr, Tehran, Yasuj and Sistan and Baluchestan city hospitals. (1, 6, 2225). The fraction of hazardous wastes in Sylhet City, Dhanka City In India, USA, Netherlands, Germany, Sweden and Denmark have been reported to be approximately $22 \%$, $16 \%, 28 \%, 5 \%, 14 \%, 8 \%$ and $27 \%$, respectively (17).

In our study, it was revealed that in Amol's hospitals the rate of hazardous waste generation is high and this necessitates more attention to proper separation of waste sat source generation. The disposal methods of medical waste in the studied hospitals were the application of incinerators in hospitals $\mathrm{B}$ and $\mathrm{C}$ and the use of a steam autoclave in hospital A. Based on a literature review, the use of a steam autoclave for the decontamination of medical waste is more efficient than incineration. As medical waste has hazardous and infectious properties, thus, they must be disposed of separately from the non-hazardous waste. Workers that handle and collect medical waste should be properly acquainted with the dangers that it poses, as mismanagement of medical waste can result in irreversible environmental health impacts. Finally, the proper separation and collection of hospital wastes (hazardous and non-hazardous) will decrease investment and operation costs of the incineration plant and pollution emissions. The physical composition of waste in the studied hospitals of Amol City were; plastic (30.2\%), glass (4.8\%), textiles (13.4\%), paper (17.9\%), metal (1.07\%), organic waste (17.8\%) and other materials (14.7\%). In other Iranian hospitals the physical components of medical waste were; paper (14\%), glass (8\%), metal (2\%), plastic (29\%), organic waste (31\%) and textiles (16\%) (26).

In conclusion, in Amol City hospitals, the average rate of hospital wastes were $3.1 \mathrm{~kg} /$ bed-day, of this about $51 \%$ is hazardous waste that must be disposed of using proper methods. The physical component analysis of the studied hospital waste showed paper with $17.9 \%$ was highest and metals with $1.07 \%$ had the lowest components.

\section{Acknowledgements}

The authors gratefully acknowledge the financial sup- port of the Research Department of Babol University of Medical Sciences.

\section{Authors' Contribution}

Authors worked equally.

\section{Financial Disclosure}

None declared.

\section{Funding/Support}

None declared.

\section{References}

1. HabibZadeh S, AdibHesami M, Mahmoudifar Y. Hospital waste management in hospitals, Bukan, Mahabad, Saghez, myandvoab. J Health Manage Res. 2006;9(26):57-62.

2. Taru P, Kuvarega A. Solid medical waste management. The case of Parirenyatwa Hospital, Zimbabwe. Rev Biomed. 2005;16:153-8.

3. Mahmoudiyeh M. Hospital infection control, Tehran: Tehran publishing and printing institute. 2004.

4. Omrani Q. Solid waste. Tehran Islam Azad Univ. 1980;1:42-5.

5. Salkin IE, Krisiunas W. Turnberg, Medical and infectious waste management. J Americ Biol Safe Asso. 2000;5(2):54-62.

6. Rayegan Shirazi A, Mary Aryad H, Malekzadeh J. Review the status of hospital waste management Yasuj in 2006. bringing knowledge. 2008;13(1):105-13.

7. Omrani GA, Atabi F, Sadeghi M, Banaei Ghah Farokhi B. Comparison between economical,hygienic and technical aspects of three methods of hospital wastes disposal including sterilization,incineration and sanitary landfill in Shahr-e-kord. Environ Technol Sc. 2007;9(2):23-8.

8. Afshar M, Aghaie L. Management of Hospital residues in Mahshahr port petrochemistry industries. 2th expertism congress of environmental engineering; 2008; Mahshahr,Iran.

9. Mousavi M. Hospital infections. Qazvin: Qazvin Faculty of Medical Sciences Publications; 2004.

10. Altin S, Altin A, Elevli B, Cerit O. Determination of Hospital Waste Composition and Disposal Methods: a Case Study. Polish J Enviro Study. 2003;12(2):251-5.

11. Fadaii A, Khorram F. Survey of hospital residuals in Golestan province in 2006. 10th national conference of environmental health; 2007; Hamadan, Iran

12. Asadi A, Moghadda H. Dioxin in environment. 8th National congress of Environmental health; 2005; Tehran.

13. Abdulla F, Abu Qdais H, Rabi A. Site investigation on medical waste management practices in northern Jordan. Waste Manag. 2008;28(2):450-8.

14. Da Silva CE, Hoppe AE, Ravanello MM, Mello N. Medical wastes management in the south of Brazil. Waste Manag. 2005;25(6):600-5.

15. Patil AD, Shekdar AV. Health-care waste management in India. $J$ Environ Manage. 2001;63(2):211-20.

16. Patil GV, Pokhrel K. Biomedical solid waste management in an Indian hospital: a case study. Waste Manag. 2005;25(6):592-9.

17. Kaisar AlamSarkar MS, AzizulHaque M, Khan T. Hospital waste management in Sylhet city. ARPN JEng Applied Sc. 2006;1(2):32-40.

18. Visvanathan C. Environmental Engineering \& Management Program Asian Institute of Technology in Medical Waste Management Issues in Asia. Tokyo; 2006; Available from: http:|| www.google.com/url?sa $=\mathrm{t} \& \mathrm{rct}=\mathrm{j} \& \mathrm{q}=\& \mathrm{esrc}=\mathrm{s} \&$ source $=$ web\&cd $=1 \&$ cad=rja\&ved=0CB 4 QFjAA\&url=http\%3A\%2F\%2Fwww.serd.ait. ac.th\%2Fpages\%2Ffos.php\%3Ffos\%3Deem\&ei=5tdNUIbCE8SmhAf qnIDYCQ\&usg=AFQjCNFmr6XsbbkUyewszwwOuofombo-_w.

19. Hatam N, Askarian M, Mohammadi M. Survey of the results of solid waste management quality gradation template in hospi- 
tal of Shahid Faghihi in Shiraz during 2005. J Health Manage Res. 2006(26):26-31.

20. NouriSepehr M. Evaluation of hospital waste in Semnan province. Tehran, Iran. in solid waste management and its health problems; 1990; Tehran, Iran.

21. Yaghoubifar M, Khamirchi R. Investigation and disposal of hospital wastes in hospitals and health centers of Sabzevar. J Sabzevar Univ Med Sci. 2007;14(2):128-34.

22. Bazrafshan E, Mostafapoor FK. Survey of medical waste characterization and management in Iran: a case study of Sistan and Baluchestan Province. Waste Manag Res. 2011;29(4):442-50.

23. Masoumbeigi H, KarimiZarchi A, Tajik J. Survey of the results of solidwaste management quality gradation template in Shahid Faghihi hospital in Shiraz during 2005. Med militar. 2007;9(2):129-38.
24. Mirzaie K, Zahmatkesh S. Hospital solidwastes disposal status in booshehr province hospitals. Medicine of South. 2007(2):190-98.

25. Khayal A. The regional solid waste exchange of information and expertise network in Mashreq and Maghreb countries. 2010; 1-50]. Available from: http://www.google.com/url?sa=t\&rct=j\&q $=\&$ esrc $=s \&$ source $=$ web\&cd $=8 \& c a d=r j a$ red $=0$ CEUQFjAH\&url $=$ http\%3A\%2F\%2Fwww.swapp.org.ph\%2Fwhats-new\%2Fupcomingevents\%2F348-marrakech-declaration-towards-qgreeningq-thewaste-sector-sweep-net-second-regional-forum\&ei=IgNPUKNOMm3hAf6loDgBg\&usg=AFQjCNHT80oYLNvCUvqsoCtUw26Y HCDktA.

26. Dehghani MH, Azam K, Changani F, Dehghani Fard E. Assessment of Medical Waste Management in Educational Hospitals of Tehran University Medical Sciences.J Environ Health Sci. 2008;5(2):131- 